\title{
Consumption of a high-fat meal containing cheese compared with a vegan alternative lowers postprandial C-reactive protein in overweight and obese individuals with metabolic abnormalities: a randomised controlled cross-over study
}

\author{
Elieke Demmer ${ }^{1}$, Marta D. Van Loan ${ }^{1,2}$, Nancy Rivera ${ }^{1}$, Tara S. Rogers ${ }^{1}$, Erik R. Gertz ${ }^{2}$, \\ J. Bruce German ${ }^{3,4}$, Angela M. Zivkovic ${ }^{1}$ and Jennifer T. Smilowitz ${ }^{3,4} *$ \\ ${ }^{1}$ Department of Nutrition, University of California Davis, Davis, CA, USA \\ ${ }^{2}$ USDA/ARS Western Human Nutrition Research Center, Davis, CA, USA \\ ${ }^{3}$ Foods for Health Institute, University of California, Davis, CA, USA \\ ${ }^{4}$ Department of Food Science \& Technology, University of California, Davis, CA, USA
}

(Received 18 July 2015 - Final revision received 17 November 2015 - Accepted 11 December 2015)

Journal of Nutritional Science (2016), vol. 5, e9, page 1 of 12

doi:10.1017/jns. 2015.40

Abstract

Dietary recommendations suggest decreased consumption of SFA to minimise CVD risk; however, not all foods rich in SFA are equivalent. To evaluate the effects of SFA in a dairy food matrix, as Cheddar cheese, $v$. SFA from a vegan-alternative test meal on postprandial inflammatory markers, a randomised controlled cross-over trial was conducted in twenty overweight or obese adults with metabolic abnormalities. Individuals consumed two isoenergetic highfat mixed meals separated by a 1- to 2 -week washout period. Serum was collected at baseline, and at 1, 3 and $6 \mathrm{~h}$ postprandially and analysed for inflammatory markers (IL-6, IL-8, IL-10, IL-17, IL-18, TNF $\alpha$, monocyte chemotactic protein-1 (MCP-1)), acute-phase proteins C-reactive protein (CRP) and serum amyloid-A (SAA), cellular adhesion molecules and blood lipids, glucose and insulin. Following both high-fat test meals, postprandial TAG concentrations rose steadily $(P<0.05)$ without a decrease by $6 \mathrm{~h}$. The incremental AUC (iAUC) for CRP was significantly lower $(P<0.05)$ in response to the cheese compared with the vegan-alternative test meal. A treatment effect was not observed for any other inflammatory markers; however, for both test meals, multiple markers significantly changed from baseline over the $6 \mathrm{~h}$ postprandial period (IL-6, IL-8, IL-18, TNF $\alpha$, MCP-1, SAA). Saturated fat in the form of a cheese matrix reduced the iAUC for CRP compared with a vegan-alternative test meal during the postprandial $6 \mathrm{~h}$ period. The study is registered at clinicaltrials.gov under NCT01803633.

Key words: Dairy products: Inflammation: Metabolic syndrome: Obesity: Palm oil: Postprandial metabolism: Vegan diets

One independent risk factor for CVD is postprandial inflammation, or inflammation in the hours immediately following a meal (for a review, see Burdge \& Calder ${ }^{(1)}$ ). Consumption of a meal promotes a transient inflammatory response, the intensity and duration of which is determined by the composition of the meal (for a review, see Margioris ${ }^{(2)}$ ). A high-fat meal increases
TAG- rich lipoproteins, a phenomenon known as postprandial lipaemia, which is linked to CVD risk ${ }^{(3)}$. Both postprandial inflammatory and lipaemic responses contribute to a chronic pro-inflammatory state observed in metabolically abnormal individuals, termed metabolic inflammation, which further exacerbates CVD risk (for a review, see Margioris $^{(2)}$ ).

Abbreviations: CH, cheese; CRP, C-reactive protein; HOMA-IR, homoeostasis model assessment of insulin resistance; iAUC, incremental AUC; MCP-1, monocyte chemotactic protein-1; SAA, serum amyloid-A; sICAM, soluble intracellular adhesion molecule; VA, vegan alternative; WC, waist circumference.

* Corresponding author: J. T. Smilowitz, fax +1 530752 4759, email jensm@ucdavis.edu 
Observational studies have linked saturated fat consumption with increased risk for CVD development ${ }^{(4,5)}$. The specific effects of varying fatty acid composition have been investigated extensively, with the latest consensus purporting that MUFA and PUFA are beneficial whereas SFA and trans-fats are deleterious in terms of plasma lipid profiles and CVD risk (for a review, see Erkkilä et al. ${ }^{(6)}$ ). Decreasing SFA intake has been the cornerstone of dietary recommendation for several decades, including the current Dietary Guidelines for Americans $2010^{(7)}$. However, decreasing SFA intake may not lower CVD risk in a subset of the population ${ }^{(8)}$. In fact, a recent meta-analysis of twenty-two prospective studies found that consumption of certain dairy foods that are high in SFA, specifically cheese, was found to be inversely associated with CVD risk ${ }^{(9)}$. The postprandial effect of dairy foods is more than the sum of its parts. When analysed individually, dairy-derived proteins ${ }^{(10)}$, SCFA $^{(11)}$, bacteria in fermented dairy products (for a review, see Settanni \& Moschetti ${ }^{(12)}$ ), and milk fat globule membrane ${ }^{(13)}$, have shown favourable or neutral effects on CVD risk. However, little is known about the combination of components in cheese and their interactions, known as the food matrix (for a review, see Jacobs et al. ${ }^{(14)}$ ), on postprandial lipaemia and inflammation. The majority of studies examining postprandial inflammation in response to high-fat dietary challenges compared SFA with MUFA and PUFA, but not with other high-SFA foods that varied in fatty acid composition ${ }^{(15,16)}$. Additionally, the consumption of SFA from dairy products in the context of a complex matrix such as cheese rather than as just milk, cream or butter have not been examined. This is surprising considering that cheese is the primary source of SFA in the American diet ${ }^{(17)}$. A recent study documented that approximately $5 \%$ of US adults are vegetarian, of whom about half are vegan ${ }^{(18)}$. These numbers have doubled from 2009 to 2011. The Dietary Guidelines Advisory Committee recently noted that a diet higher in plant-based foods is more health promoting than the current US $\operatorname{diet}^{(19)}$. This is echoed in a position paper from the Academy of Nutrition and Dietetics reporting that appropriately planned plant-based diets may help prevent and treat certain chronic diseases ${ }^{(20)}$. While there is research supporting a plant-based diet for optimal health, this type of dietary pattern can still include plant-based saturated fats, such as palm oil. Yet the postprandial effects of high-fat meals containing SFA from plant sources (i.e. palm oil) have not been examined in human subjects. In mice, consumption of a diet enriched with palm oil induced the highest levels of inflammation compared with other lipids tested, including milk fat ${ }^{(21)}$. Given the increasing interest in plantbased diets by the public, this study set out to address the gap in knowledge about the effects of dietary saturated fat from plant sources $v$. from dairy sources on postprandial inflammation. Specifically, the aim of this study was to determine the effects of consuming two mixed isoenergetic meals high in SFA from cheese compared with a non-dairy cheese alternative plus palm oil on postprandial inflammatory and metabolic markers. We hypothesised that consumption of a meal high in SFA from Cheddar cheese in overweight and obese individuals with metabolic abnormalities would result in lower circulating pro-inflammatory markers in the postprandial state compared with a meal with equal amounts of SFA from palm oil plus a non-dairy cheese substitute.

\section{Methods}

\section{Participants}

A total of twenty adults (seven men and thirteen women) were recruited. Inclusion criteria were: age 18-65 years, and either a BMI between 25 and $29.9 \mathrm{~kg} / \mathrm{m}^{2}$ plus two traits of the metabolic syndrome defined by the American Heart Association as waist circumference $(W C)>40$ inches $(>102 \mathrm{~cm})$ for men and 35 inches $(>89 \mathrm{~cm})$ for women, fasting plasma TAG $\geq 150$ $\mathrm{mg} / \mathrm{dl}(\geq 1.69 \mathrm{mmol} / \mathrm{l})$, fasting plasma HDL-cholesterol $<40 \mathrm{mg} / \mathrm{dl}(<1.03 \mathrm{mmol} / \mathrm{l})$ for men and $<50 \mathrm{mg} / \mathrm{dl}(<1.29$ $\mathrm{mmol} / \mathrm{l}$ ) for women, blood pressure $\geq 130 / 85 \mathrm{mmHg}$, and fasting glucose $\geq 100 \mathrm{mg} / \mathrm{dl}(\geq 5.6 \mathrm{mmol} / \mathrm{l})^{(22)}$, or obese (BMI between 30 and $39.9 \mathrm{~kg} / \mathrm{m}^{2}$ ). Participants' insulin sensitivity was determined from their fasting plasma glucose and insulin using the homoeostasis model assessment of insulin resistance (HOMA-IR) with 2.6 or greater as a cut-off point of insulin resistance ${ }^{(23)}$. Participants' inflammation status was determined with the measurement of fasting circulating CRP concentrations at $3 \mathrm{mg} / 1$ or above as associated with increased CVD risk ${ }^{(24)}$. Exclusion criteria included immune-related diseases, gastrointestinal disorders, cancer, type 2 diabetes, use of over-the-counter anti-obesity agents or corticoid steroid within the last 12 weeks, daily use of anti-inflammatory pain medication, self-reported eating disorder, poor vein assessment determined by the phlebotomist, known allergy or intolerance to study food, vegetarian, consume $>1$ serving of fish per week, $>14 \mathrm{~g}$ of fibre per $1000 \mathrm{kcal}(4184 \mathrm{~kJ}) / \mathrm{d}$, $<16: 1$ of total dietary $n-6: n-3$ ratio, $>1 \%$ of daily energy as trans-fats, initiation of fish, krill, flax, borage or primrose seed oils within the last 12 weeks, dietary supplements of concentrated soya isoflavones, resveratrol, other polyphenols, initiation of statin therapy within the last 12 weeks, $>10 \%$ weight loss or gain during the past 6 months, initiation of an exercise programme in the last month, plan to become pregnant in the next 6 months, pregnancy or lactation, recent initiation, change, or cessation of hormonal birth control within the last 12 weeks, and use of tobacco products. To establish fulfillment of the enrolment criteria subjects completed a questionnaire regarding their health history, diet and medication, completed an online FFQ, provided a fasting blood sample for analysis of blood lipids and glucose, and were assessed for weight, height and WC at the screening visit.

The Institutional Review Board of the University of California at Davis approved the study protocol, and all participants gave written informed consent prior to starting the study. The study is registered at clinicaltrials.gov under NCT01803633.

\section{Study design}

A randomised, cross-over design was used in which investigators were blind to treatment order. All participants received 


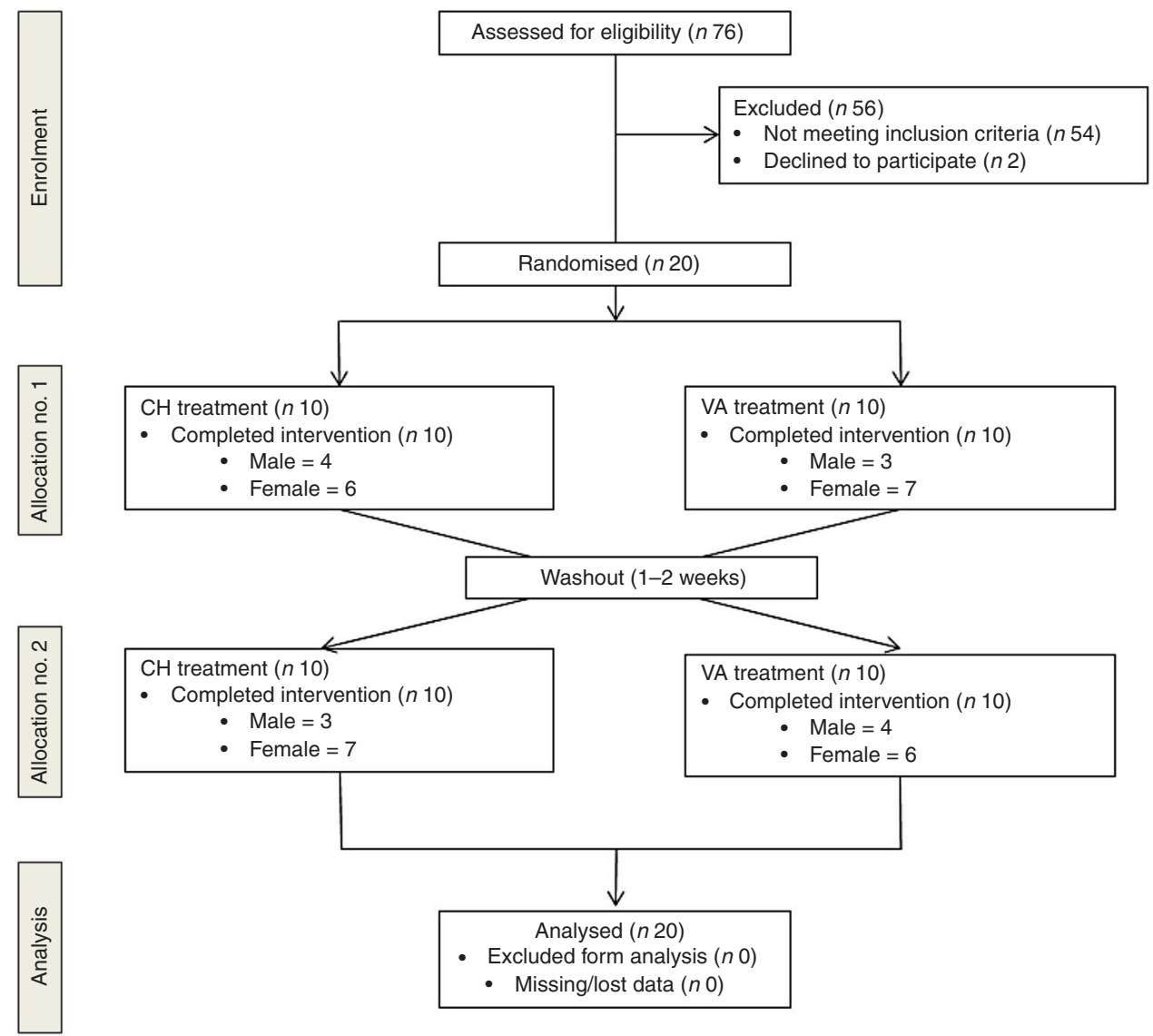

Fig. 1. Enrolment and follow up of participants in the randomised cross-over trial. $\mathrm{CH}$, Cheddar cheese treatment; VA, vegan-alternative treatment.

both treatments. To avoid any interaction effects a 1 - to 2 -week washout period was observed between treatments. Treatment order was randomly assigned using a random allocation sequence generator (randomization.com; seed\# 4234) (Fig. 1).

Volunteers were instructed to avoid alcohol consumption, non-steroidal inflammatory drug use, and any anti-inflammatory supplements such as fish, krill, flax, borage or primrose seed oils $72 \mathrm{~h}$ prior to each test day. Volunteers were instructed to avoid seafood, and were asked to record everything they consumed $24 \mathrm{~h}$ before the test day, not to exercise, and not to consume anything past 20.00 hours. We analysed the 1-d dietary records using the Nutrition Data System for Research (NDSR; University of Minnesota) to ensure that participants complied with pre-study dietary instructions.

After a 10-12 h fast participants arrived at the Western Human Nutrition Research Center. Upon arrival volunteers turned in their 1-d food record, filled out a modified gastrointestinal questionnaire ${ }^{(25)}$, provided a urine sample and fasted blood draw via venepuncture. Measurements for blood pressure, heart rate, weight and WC were taken. Participants then consumed the high-fat breakfast challenge within $20 \mathrm{~min}$. Postprandial blood draws and urine samples were collected at 1,3 and $6 \mathrm{~h}$. These time points were chosen based on previous studies demonstrating peak cytokine concentrations observed 3 or $6 \mathrm{~h}$ after a high-fat meal challenge ${ }^{(16)}$ and oxylipins and eicosanoids change at 1 and $6 \mathrm{~h}$ from baseline ${ }^{(26,27)}$.

Throughout the test day participants were not allowed to consume any food, but could drink bottled water ad libitum.
Participants either stayed at the research centre or left between blood draws to attend classes or return to work. To minimise physical activity, if participants left the research facility they did so by car, not by foot or bicycle, and returned approximately $15 \mathrm{~min}$ and rested for $10 \mathrm{~min}$ prior to the next blood draw.

\section{Dietary challenges}

The dietary challenges consisted of grilled sandwiches served with a blended beverage. The cheese $(\mathrm{CH})$ test meal consisted of medium Cheddar cheese (Tillamook Medium Cheddar Cheese) while the vegan alternative (VA) consisted of Daiya Cheddar cheese (Daiya). Both sandwiches were made with $100 \%$ Whole Wheat Sandwich Thins (Oroweat). Each meal was paired with a blended beverage to allow for the matching of energy, total fat, carbohydrates and protein (Supplementary Table S1).

Each of the two meal challenges provided $40 \%$ of the participant's total energy intake. Energy intake was determined by using the National Academy of Sciences equation from the Institute of Medicine Dietary Reference Intake that takes physical activity into account in addition to sex, age, weight and height ${ }^{(28)}$. Physical activity was determined using the Baecke Physical Activity questionnaire, which assesses habitual physical activity and identifies three components of physical activity: work, sport and leisure time excluding sport ${ }^{(29)}$.

Each meal consisted of about $50 \%$ fat, about $40 \%$ carbohydrates, and about $10 \%$ protein and delivered between 45 and $75 \mathrm{~g}$ of fat depending on the individual's energy intake. 
The Cheddar cheese provided $44 \%$ of the fat in the $\mathrm{CH}$ meal and palm oil provided $38 \%$ of the fat in the non-dairy cheese substitute meal. The meals were isoenergetic, had the same macronutrient composition as well as similar MUFA, PUFA and SFA composition (Table 1). The only difference between the test meals was individual fatty acid composition, the matrix in which it was delivered, dietary cholesterol and Ca concentrations. Participants were instructed to eat everything on their plate and rinse their blended beverage cup with water, then drink the rinse water.

\section{Blood analyses}

Whole blood was collected at the Western Human Nutrition Research Center by a trained phlebotomist for each time point. Whole blood was centrifuged in a tabletop ultracentrifuge for $10 \mathrm{~min}$ at $4^{\circ} \mathrm{C}$ at $1300 \mathrm{~g}$ within $30 \mathrm{~min}$ of collection. Plasma was immediately separated into $1.5 \mathrm{ml}$ aliquots, and immediately frozen at $-70^{\circ} \mathrm{C}$ until analysis. Serum was isolated and transferred into $1.5 \mathrm{ml}$ aliquots after clotting for $30 \mathrm{~min}$ on ice and centrifugation and immediately frozen at $-70^{\circ} \mathrm{C}$ until analysed.

\section{Inflammatory markers}

Serum collected at $0,1,3$ and $6 \mathrm{~h}$ was used to analyse cytokines (IL-10, IL-17, IL-1 $\beta$, IL-2, IL-6, IL-8, monocyte chemotactic protein-1 (MCP-1), TNF $\alpha$ ), as well as the acute-phase proteins (C-reactive protein (CRP), serum amyloid-A (SAA)), and vascular injury molecules soluble intracellular adhesion molecule (sICAM) and soluble vascular adhesion molecule. Plasma was used to measure IL-18 concentrations. Analysis of all inflammatory markers was completed using an electrochemiluminescence detection system using multiarray technology (SECTOR Imager 2400; Meso Scale Discovery) according to the manufacturer's instructions. In brief, this system uses multi-array ninety-six-well plates with multi-electrodes per well. Each electrode has a different capture antibody, allowing for the analysis of multiple markers of interest at once. The assay procedure is similar to that of a classic sandwich ELISA. A small amount of sample $(25-50 \mu \mathrm{l})$ serum or plasma is added to each well. The markers of interest bind to the precoated capture antibodies. To complete the 'sandwich' a detection antibody that is conjugated with a label is added and binds to the analyte. Finally the addition of a read buffer allows for the activation of the label on the detection antibody, resulting in illumination after electrochemical stimulation via voltage that runs through the plate in the reader. The instrument measures the intensity of the light to quantify a measure of each analyte.

\section{Metabolic parameters}

Plasma glucose, insulin and a lipid panel including TAG, total cholesterol, HDL-cholesterol, LDL-cholesterol, HDL:LDL ratio and non-HDL-cholesterol were assessed by the clinical laboratory at the University of California Medical Center (Sacramento, CA) at baseline and at 1, 3 and $6 \mathrm{~h}$ after consuming the high-fat challenge meal.
Table 1. Nutrient composition of the test meals $\dagger$ (Mean values and standard deviations)

\begin{tabular}{|c|c|c|c|c|}
\hline & \multicolumn{2}{|c|}{$\mathrm{CH}$ meal } & \multicolumn{2}{|c|}{ VA meal } \\
\hline & Mean & SD & Mean & SD \\
\hline Energy (kcal) & 1002.9 & 114.5 & $1002 \cdot 1$ & 113.9 \\
\hline Energy (kJ) & $4196 \cdot 0$ & 478.8 & $4192 \cdot 6$ & $476 \cdot 3$ \\
\hline \multicolumn{5}{|l|}{ Total carbohydrate } \\
\hline$g$ & $103 \cdot 7$ & $11 \cdot 8$ & $105 \cdot 0$ & 11.9 \\
\hline$\%$ total energy & 39.3 & 0.0 & 39.0 & 0.0 \\
\hline \multicolumn{5}{|l|}{ Total protein } \\
\hline g & $27 \cdot 8$ & $3 \cdot 2$ & 28.8 & 3.3 \\
\hline$\%$ total energy & $11 \cdot 0$ & 0.0 & $10 \cdot 2$ & 0.0 \\
\hline \multicolumn{5}{|l|}{ Total fat } \\
\hline $\mathrm{g}$ & $56 \cdot 6$ & 6.5 & $57 \cdot 9$ & $6 \cdot 6$ \\
\hline$\%$ total energy & $49 \cdot 6$ & 0.0 & 50.8 & 0.0 \\
\hline \multicolumn{5}{|l|}{ Total SFA } \\
\hline g & $19 \cdot 2$ & $2 \cdot 2$ & $19 \cdot 7$ & $2 \cdot 2$ \\
\hline$\%$ total energy & $16 \cdot 8$ & 0.0 & $17 \cdot 2$ & 0.0 \\
\hline \multicolumn{5}{|l|}{ Total MUFA } \\
\hline g & 21.1 & 2.4 & 21.7 & 2.5 \\
\hline$\%$ total energy & 18.6 & 0.0 & 19.1 & 0.0 \\
\hline \multicolumn{5}{|l|}{ Total PUFA } \\
\hline g & 13.4 & 1.5 & 13.8 & 1.6 \\
\hline$\%$ total energy & 11.8 & 0.0 & $12 \cdot 1$ & 0.0 \\
\hline SFA 4 : 0 (butyric acid) $(\%)^{\star \star \star}$ & 1.4 & 0.0 & 0.0 & 0.0 \\
\hline SFA 6 : 0 (caproic acid) $(\%)^{\star \star \star}$ & 0.7 & 0.0 & 0.1 & 0.0 \\
\hline SFA 8 : 0 (caprylic acid) $(\%)^{\star * *}$ & 0.4 & 0.0 & 0.9 & 0.0 \\
\hline SFA 10 : 0 (capric acid) (\%) & 0.8 & 0.0 & 0.8 & 0.0 \\
\hline SFA 12 : 0 (lauric acid) $(\%)^{* * *}$ & 0.7 & 0.0 & $5 \cdot 6$ & 0.0 \\
\hline SFA 14 : 0 (myristic acid) $(\%)^{\star \star \star}$ & 4.5 & 0.0 & 2.5 & 0.0 \\
\hline SFA 16 : 0 (palmitic acid) $(\%)^{\star \star \star}$ & $16 \cdot 10$ & 0.01 & $20 \cdot 24$ & 0.02 \\
\hline SFA 18: 0 (stearic acid) $(\%)^{\star * *}$ & $7 \cdot 71$ & 0.00 & 3.28 & 0.00 \\
\hline SFA 20 : 0 (arachidic acid) $(\%)^{\star \star *}$ & 0.00 & 0.00 & 0.12 & 0.00 \\
\hline SFA 22 : 0 (behenic acid) $(\%)^{\star * *}$ & 0.22 & 0.00 & 0.15 & 0.00 \\
\hline MUFA $16: 1$ (palmitoleic acid) (\%) & 1.50 & 0.00 & 0.39 & 0.00 \\
\hline MUFA $18: 1$ (oleic acid) $(\%)^{*}$ & 34.97 & 0.02 & $36 \cdot 78$ & 0.01 \\
\hline MUFA 20 : 1 (gadoleic acid) (\%)*** & 0.22 & 0.00 & 0.37 & 0.00 \\
\hline PUFA 18 : 2 (linoleic acid) (\%) & 22.98 & 0.02 & 21.80 & 0.02 \\
\hline PUFA 18 : 3 (linolenic acid) $(\%)^{\star \star *}$ & 0.72 & 0.00 & 1.94 & 0.00 \\
\hline Cholesterol (mg) ${ }^{\star * *}$ & 79.20 & 9.01 & 0.00 & 0.00 \\
\hline Total dietary fibre $(\mathrm{g})^{\star \star *}$ & $12 \cdot 27$ & 1.39 & $15 \cdot 60$ & 1.77 \\
\hline $\mathrm{Ca}(\mathrm{mg})^{\star \star \star}$ & $487 \cdot 11$ & $55 \cdot 38$ & 129.71 & 14.75 \\
\hline
\end{tabular}

$\mathrm{CH}$, cheese; VA, vegan alternative.

Significant difference between the two meals: ${ }^{*} P<0.05,{ }^{* \star} P<0.005$, ${ }^{* * *} P<0.0005$. tComparison of the two dietary challenges. Nutrient composition was obtained using Nutrition Data System for Research (NDSR). Test meals were based on total energy expenditure thus values shown are average of all test meals $(n 20)$.

\section{Clinical characteristics}

Anthropometric data were collected at the screening visit and each test day visit. Measurements included body weight (6002 Wheelchair Scale; Scale-tronix), WC (QM2000 Measure Mate; QuickMedical), height (Ayrton Stadiometer Model S100; Ayrton Corporation), blood pressure and resting heart rate (Carescape V100 with Critikon Dura-cuf for either adults or large adults; GE Medical Instruments). BMI was calculated as $\mathrm{kg} / \mathrm{m}^{2}$.

\section{Statistical analysis}

This study was a $2 \times 4$ factorial design: two treatments $\mathrm{x}$ four time points. Sample size was calculated based on our primary outcome marker using the means and standard deviations for IL-6 from a similar human study with overweight volunteers ${ }^{(16)}$. A secondary analysis was also conducted on other 
pro-inflammatory cytokines, acute-phase proteins and vascular adhesion molecules based on previous research that showed changes in these markers in healthy participants in response to high-fat test meals containing similar amounts of fat as used in our study (for a review, see Herieka \& Erridge ${ }^{(30)}$ ).

To ensure that our sample size reflected the number of subjects needed to be $95 \%$ confident of our results, with $80 \%$ power we needed eighteen volunteers. To account for attrition $10 \%$ was added for a final sample size of twenty. All data were checked for normality visually with histograms and Q-Q plots as well as numerically with the Shapiro-Wilk test. Data were transformed as needed prior to conducting statistical analysis. For cytokines with $<10 \%$ of samples below the detection limit (IL-17 only) the value recorded was the lowest limit of detection provided by the manufacturer and divided by 10 . For dependent variables with $>10 \%$ of the data below the detection limit these markers were excluded from statistical analysis (IL-1 $\beta$ and IL-2).

Dietary data between treatments were compared using a paired two-tailed $t$ test. Differences in baseline concentration between treatments were tested using a paired sample twotailed $t$ test. A mixed linear model was conducted with treatment and time as fixed factors, subjects as the random effect and treatment $\times$ time as the interaction term. If time was significant, multiple comparison post hoc analysis with Bonferroni correction was carried out to compare the concentrations at $0 \mathrm{v}$. $1 \mathrm{~h}, 0 v .3 \mathrm{~h}, 0 v .6 \mathrm{~h}, 1 v .3 \mathrm{~h}, 1 v .6 \mathrm{~h}$, and $3 v .6 \mathrm{~h}$.

The incremental AUC (iAUC, area above baseline) and decremental AUC (area below baseline) using the conventional trapezoid method were used to compare postprandial responses between groups (response to test meals) ${ }^{(31)}$. The iAUC was chosen over the total AUC because it reflects the postprandial rise of metabolite concentrations above the non-zero fasting value ${ }^{(32)}$. iAUC between $\mathrm{CH}$ and VA groups were compared via paired $t$ tests and ANCOVA with subject as the random variable, treatment as the fixed factor and baseline CRP concentrations as the covariate.

We conducted secondary analyses to determine if preexisting clinical conditions affected the inflammatory response to the high-fat meal challenge. We coded subjects for high $v$. low baseline CRP levels known to be associated with increased vascular risk ( $<3 \mathrm{mg} / 1, n 10$; or $>3 \mathrm{mg} / 1, n 10)$. ANCOVA was used to identify statistically significant differences in postprandial inflammatory markers between treatments using baseline values of CRP as the covariate.

Differences were considered significant at $P<0.05$. Statistical analyses were performed using SPSS version 20.0 software for Macintosh (SPSS).

\section{Results}

\section{Subject characteristics}

A total of seventy-six participants underwent screening. As shown in Fig. 1, twenty subjects were randomly assigned to one of two treatment groups in a cross-over design: $\mathrm{CH}$ ( $n$ 20) and VA ( $n$ 20). After a 1- to 2-week washout period each subject crossed over to the remaining treatment. All subjects completed both treatment arms with no attrition.
The baseline characteristics of the subjects are shown in Table 2 and metabolic characteristics of each participant are found in Supplementary Table S2. Our study population was predominantly female $(65 \%)$ and Caucasian $(75 \%)$. With respect to the metabolic syndrome, six of the twenty participants had the metabolic syndrome with three or more of the five diagnostic traits, seven participants had two of the five traits, and seven participants had only one trait. When assessing their metabolic and inflammatory status, fourteen of the twenty participants were considered insulin resistant with a HOMA-IR $>2 \cdot 6$; ten of the twenty participants had a high baseline CRP concentration ( $>3 \mathrm{mg} / \mathrm{l})$; and six of the twenty participants had both a HOMA-IR $>2.6$ and baseline CRP concentration above $3 \mathrm{mg} / \mathrm{l}$. Additionally, thirteen of the twenty participants had a BMI of $30 \mathrm{~kg} / \mathrm{m}^{2}$ or greater and were abdominally obese (WC $>35$ inches $(>89 \mathrm{~cm})$ for women and $>40$ inches $(>102 \mathrm{~cm})$ for men).

\section{Dietary intake}

Dietary analysis of the 1-d food record completed prior to each test day revealed no significant differences in consumption of macro- and micronutrients (data not shown).

\section{Metabolic parameters}

Baseline and postprandial changes for metabolic markers (total cholesterol, HDL, LDL, TAG) are shown in Table 3. No time $\times$ treatment interaction or main effect of treatment were observed for any of these markers; however, there was a significant difference over time for all markers.

\section{Postprandial glycaemia}

At baseline, insulin concentrations did not differ between test days $(P=0 \cdot 8)$ while glucose concentrations did $(P=0.004)$; however, since there was no treatment effect this statistical difference was considered a random occurrence. Following each meal, there was a rapid increase in both glucose and insulin from 0 to $1 \mathrm{~h}(P=0.029$ and $P<0.0005$, respectively) followed by a decrease from 1 to $3 \mathrm{~h}(P<0.0005$ for both $)$ and an increase in glucose from 3 to $6 \mathrm{~h}(P=0 \cdot 01)$. The glucose $(P=0.602)$ and insulin $(P=0.908)$ responses did not differ between the treatments (Fig. 2).

\section{Postprandial lipaemia}

Fasting/baseline TAG concentrations were comparable between the two treatments $(P=0 \cdot 245)$. After meal consumption, postprandial TAG concentration rose steadily $(P<0.05$ for all time points: $0-1,0-3,0-6,1-3,1-6$, and $3-6 \mathrm{~h}$ ) with no sign of a decrease at the $6 \mathrm{~h}$ time point (Fig. 3).

\section{Inflammatory markers}

IL-1 $\beta$ and IL-2 were below the detection limit (for about 70 and $35 \%$ of samples, respectively) and therefore, excluded from the statistical analysis. Similar results for these two 
Table 2. Subject baseline characteristics* (Mean values and standard deviations)

\begin{tabular}{|c|c|c|c|c|}
\hline & Mean & SD & MetS criteria† & Range \\
\hline Age (years) & 49 & 11 & & $24-64$ \\
\hline Participants with high CRP (years) $\ddagger$ & $50 \cdot 6$ & $12 \cdot 3$ & & $24-64$ \\
\hline Participants with low CRP (years)‡ & 47.9 & 9.4 & & $25-57$ \\
\hline Weight (kg) & $90 \cdot 5$ & 9.5 & & $66 \cdot 1-109 \cdot 0$ \\
\hline Height (m) & 1.7 & 0.1 & & $1.5-1.8$ \\
\hline $\mathrm{BMI}\left(\mathrm{kg} / \mathrm{m}^{2}\right)$ & $31 \cdot 7$ & 2.9 & & $24.4-37.1$ \\
\hline WC (inches) & 38.7 & $2 \cdot 4$ & & $32-42 \cdot 4$ \\
\hline WC, males (inches)§ & 39.4 & 1.3 & $>40$ & $37 \cdot 2-41$ \\
\hline WC, females (inches)§ & 38.3 & $2 \cdot 8$ & $>35$ & $32-42.4$ \\
\hline WC $(\mathrm{cm})$ & 98.3 & $6 \cdot 1$ & & $81-107 \cdot 7$ \\
\hline WC, males $(\mathrm{cm}) \S$ & $100 \cdot 1$ & 3.3 & $>102$ & $94.5-104.1$ \\
\hline WC, females $(\mathrm{cm}) \S$ & $97 \cdot 3$ & $7 \cdot 1$ & $>89$ & $81 \cdot 3-107 \cdot 7$ \\
\hline Systolic BP (mmHg) & 127 & $14 \cdot 1$ & $\geq 130$ & $98-151.5$ \\
\hline Diastolic BP (mmHg) & $78 \cdot 1$ & 9 & $\geq 85$ & $57-98.5$ \\
\hline \multicolumn{5}{|l|}{ HDL-cholesterol } \\
\hline $\mathrm{mg} / \mathrm{dl}$ & $45 \cdot 9$ & 9.7 & & $31-60$ \\
\hline $\mathrm{mmol} / \mathrm{l}$ & 1.19 & 0.25 & & $0.80-1.55$ \\
\hline \multicolumn{5}{|l|}{ HDL-cholesterol, male§ } \\
\hline $\mathrm{mg} / \mathrm{dl}$ & 41.9 & $10 \cdot 3$ & $<40$ & $31-56$ \\
\hline $\mathrm{mmol} / \mathrm{l}$ & 1.08 & 0.27 & $<1.03$ & $0.80-1.45$ \\
\hline \multicolumn{5}{|l|}{ HDL-cholesterol, female§ } \\
\hline $\mathrm{mg} / \mathrm{dl}$ & $48 \cdot 1$ & 9.0 & $<50$ & $33-60$ \\
\hline $\mathrm{mmol} / \mathrm{l}$ & 1.24 & 0.23 & $<1.29$ & $0.85-1.55$ \\
\hline \multicolumn{5}{|l|}{ Fasting glucose } \\
\hline $\mathrm{mg} / \mathrm{dl}$ & 91.8 & 7.4 & $\geq 100$ & 78-104 \\
\hline $\mathrm{mmol} / \mathrm{l}$ & $5 \cdot 1$ & 0.4 & $\geq 5.6$ & $4 \cdot 3-5 \cdot 8$ \\
\hline \multicolumn{5}{|l|}{ Fasting TAG } \\
\hline $\mathrm{mg} / \mathrm{dl}$ & 124.4 & $45 \cdot 7$ & $\geq 150$ & $65-224$ \\
\hline $\mathrm{mmol} / \mathrm{l}$ & 1.40 & 0.52 & $\geq 1.69$ & $0.73-2.53$ \\
\hline
\end{tabular}

MetS, metabolic syndrome; CRP, C-reactive protein; WC, waist circumference; BP, blood pressure.

* Measurements taken at screening visit $(n 20)$.

$\dagger$ MetS as defined by the American Heart Associations.

$\ddagger$ High baseline CRP $n$ 10; low baseline CRP $n 10$.

$\S$ Male $n 7$; female $n 13$

particular cytokines have been observed ${ }^{(33)}$. Baseline concentrations of all markers related to inflammation were comparable between the two interventions. CRP as the iAUC was the only marker with a significant difference between treatments, with the VA meal resulting in a significantly greater overall CRP concentration $(P=0.033)$ when compared with the $\mathrm{CH}$ meal (Fig. 4). There was no treatment effect observed for any of the other inflammatory markers. However, multiple

Table 3. Concentrations of metabolic parameters before and after dietary challenge (Pooled mean values and standard deviations) ${ }^{\star}$

\begin{tabular}{|c|c|c|c|c|c|c|c|c|c|c|c|}
\hline & \multicolumn{8}{|c|}{ Time } & & & \\
\hline & \multicolumn{2}{|c|}{$\mathrm{Oh}$} & \multicolumn{2}{|c|}{$1 \mathrm{~h}$} & \multicolumn{2}{|c|}{$3 \mathrm{~h}$} & \multicolumn{2}{|c|}{$6 \mathrm{~h}$} & \multicolumn{3}{|c|}{$P$} \\
\hline & Mean & SD & Mean & SD & Mean & SD & Mean & SD & Treatment & Time & Interaction \\
\hline Total cholesterol & & & & & & & & & 0.87 & 0.001 & 0.96 \\
\hline $\mathrm{mg} / \mathrm{dl}$ & 209.0 & $44 \cdot 3$ & $215 \cdot 1$ & $45 \cdot 2$ & 209.9 & 42.4 & $212 \cdot 2$ & $45 \cdot 6$ & & & \\
\hline $\mathrm{mmol} / \mathrm{l}$ & 5.41 & $1 \cdot 15$ & 5.57 & 1.17 & 5.44 & $1 \cdot 10$ & 5.50 & $1 \cdot 18$ & & & \\
\hline HDL-cholesterol & & & & & & & & & 0.95 & 0.002 & 0.51 \\
\hline $\mathrm{mg} / \mathrm{dl}$ & $47 \cdot 3$ & $10 \cdot 9$ & $48 \cdot 3$ & 11.4 & $45 \cdot 8$ & $10 \cdot 0$ & $45 \cdot 7$ & 10.5 & & & \\
\hline $\mathrm{mmol} / \mathrm{l}$ & 1.23 & 0.28 & 1.25 & 0.30 & 1.19 & 0.26 & $1 \cdot 18$ & 0.27 & & & \\
\hline LDL-cholesterol & & & & & & & & & 0.98 & $<0.0005$ & 0.24 \\
\hline $\mathrm{mg} / \mathrm{dl}$ & 135.8 & 38.5 & $132 \cdot 4$ & 38.8 & $126 \cdot 2$ & $36 \cdot 4$ & $124 \cdot 6$ & $41 \cdot 1$ & & & \\
\hline $\mathrm{mmol} / \mathrm{l}$ & 3.52 & 1.00 & 3.43 & 1.00 & 3.27 & 0.94 & 3.23 & 1.06 & & & \\
\hline HDL:LDL & 4.6 & $1 \cdot 1$ & 4.6 & 1.0 & $4 \cdot 7$ & $1 \cdot 1$ & 4.7 & $1 \cdot 1$ & 0.93 & $<0.0005$ & 0.38 \\
\hline TAG & & & & & & & & & 0.60 & $<0.0005$ & 0.67 \\
\hline $\mathrm{mg} / \mathrm{dl}$ & 129.0 & 44.4 & 171.2 & 54.7 & 199.9 & $75 \cdot 2$ & 218.6 & 77.4 & & & \\
\hline $\mathrm{mmol} / \mathrm{l}$ & 1.46 & 0.50 & 1.93 & 0.62 & $2 \cdot 26$ & 0.85 & 2.47 & 0.87 & & & \\
\hline Non-HDL-cholesterol & & & & & & & & & 0.88 & $<0.0005$ & 0.59 \\
\hline $\mathrm{mg} / \mathrm{dl}$ & $161 \cdot 6$ & 41.7 & $166 \cdot 7$ & $42 \cdot 4$ & $164 \cdot 1$ & $40 \cdot 3$ & $166 \cdot 4$ & 43.6 & & & \\
\hline $\mathrm{mmol} / \mathrm{l}$ & 4.19 & 1.08 & 4.32 & $1 \cdot 10$ & 4.25 & 1.04 & $4 \cdot 31$ & 1.13 & & & \\
\hline
\end{tabular}

* Values are pooled means of both treatments since there was no treatment effect. 

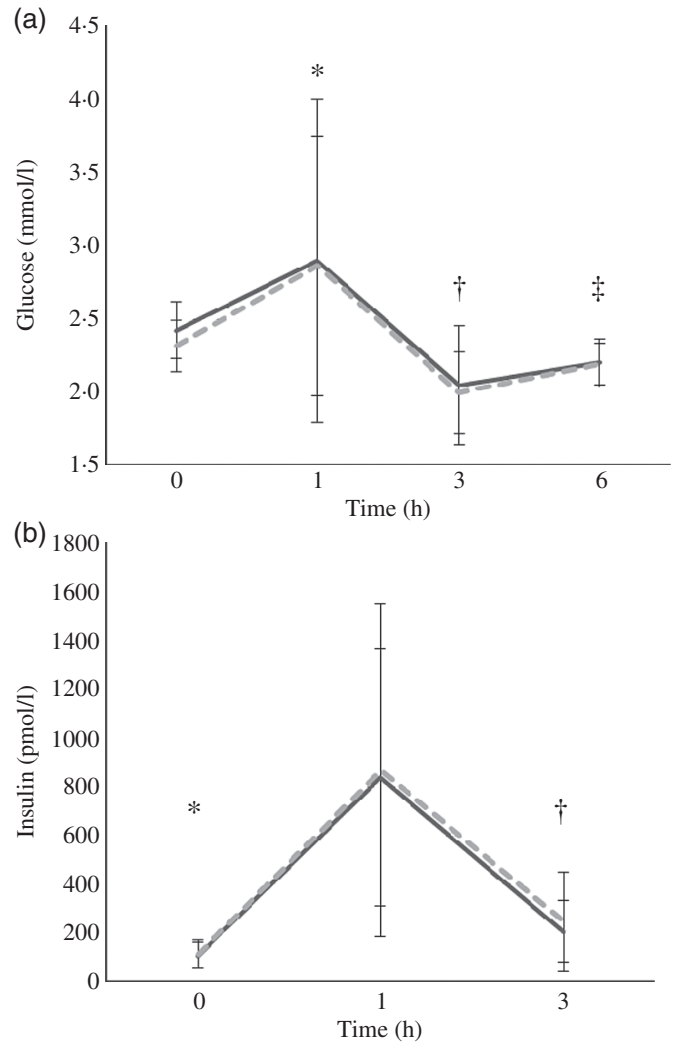

Fig. 2. Postprandial response of glucose (a) and insulin (b) before and after high-fat mixed meal rich in SFA from either vegan alternative cheese (--) or Cheddar cheese (-). Values are means, with standard deviations represented by vertical bars ( $n$ 20). * Significant difference between 0 and $1 \mathrm{~h}$ $(P<0.0005)$. $\dagger$ Significant difference between 1 and $3 \mathrm{~h}(P<0.0005)$. $\ddagger$ Significant difference between 3 and $6 \mathrm{~h}(P=0.01)$.

markers did demonstrate an effect over time; SAA peaked at 1 $\mathrm{h}$ postprandially, IL-8 peaked at $3 \mathrm{~h}$, while IL-6, IL-18, MCP-1 and TNF $\alpha$ peaked at $6 \mathrm{~h}$ postprandially (Table 4). Secondary analyses based on baseline CRP values indicated that those with pre-existing fasting CRP concentrations $\geq 3 \mathrm{mg} / 1 \mathrm{did}$ not have a different response to treatment compared with participants with baseline CRP concentrations $<3 \mathrm{mg} / \mathrm{l}$. We

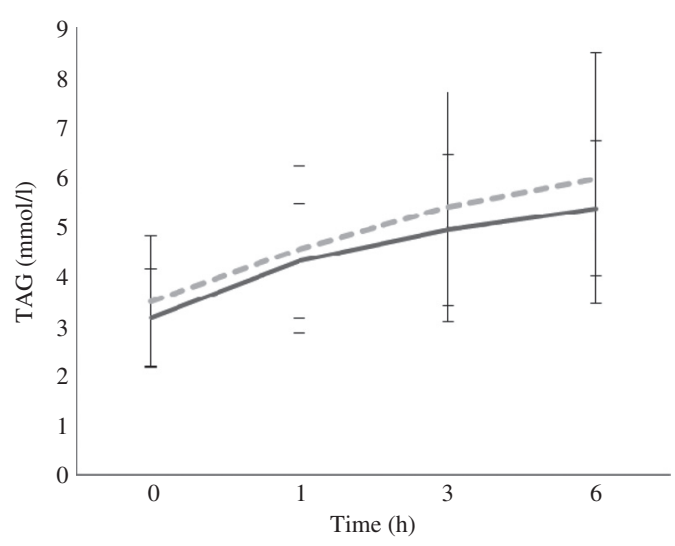

Fig. 3. Postprandial response of serum TAG after both vegan alternative (--) and Cheddar cheese (-) meals. Values are means, with standard deviations represented by vertical bars $(n 20)$. There was no difference between the treatments but there was a significant increase over time $(P<0.05)$ for all time points: $0-1,0-3,0-6,1-3,1-6$, and $3-6 \mathrm{~h}$.

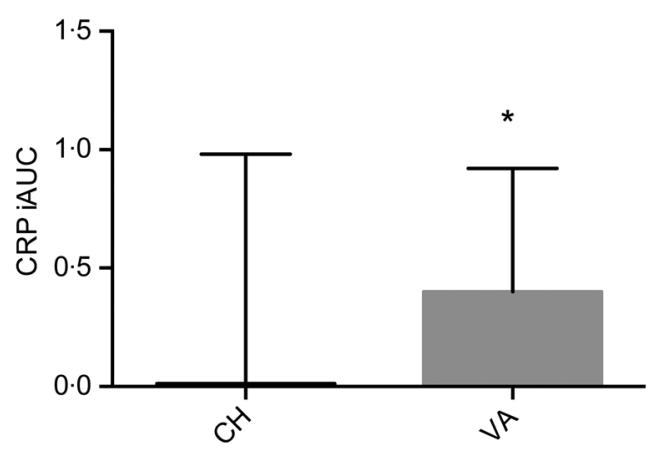

Fig. 4. Postprandial serum C-reactive protein (CRP) concentrations over the $6 \mathrm{~h}$ postprandial period after the Cheddar cheese $(\mathrm{CH})$ and vegan alternative (VA) meals. Values are means, with standard deviations represented by vertical bars. * The VA meal resulted in a significantly greater overall CRP concentration $(P=0.033)$ when compared with the $\mathrm{CH}$ meal. iAUC, incremental AUC.

conducted a secondary analysis using baseline CRP concentrations as a stratification and found that volunteers who had a baseline CRP value $>3 \mathrm{mg} / \mathrm{l}$ had significantly higher concentrations of IL-6, SAA and sICAM at each time point compared with the subjects who had baseline CRP values $<3 \mathrm{mg} / \mathrm{l}$.

\section{Discussion}

In this study, more than half $(55 \%)$ of the measured serum inflammatory markers (IL-6, IL-8, IL-18, TNF $\alpha$, MCP-1 and SAA) significantly changed over the $6 \mathrm{~h}$ postprandial period from baseline. Some of these findings are consistent and some are not consistent with previous findings. Based on the literature we had expected IL-6 to increase after the highfat challenges and peak around the $3 \mathrm{~h}$ time point, which has previously been observed in men with the metabolic syndrome $^{(34)}$, overweight, obese men and women ${ }^{(16,35,36)}$, and healthy participants ${ }^{(37,38)}$. However, to our surprise, the results presented here showed an initial decrease in serum IL-6 concentration from baseline to the $1 \mathrm{~h}$ time point after consuming both high-fat meals, followed by a significant rise at $3 \mathrm{~h}$. Manning et al. ${ }^{(36)}$ reported similar findings of a temporary decrease in IL-6 at $1 \mathrm{~h}$ after five test meals rich in cream, olive oil, rapeseed oil, potato or All-Bran in obese and healthy women, suggesting this might be due to the anti-inflammatory effects of insulin ${ }^{(39)}$. Our results support this, as insulin peaked at $1 \mathrm{~h}$, the time at which IL- 6 concentrations were lowest.

IL-8 has not been commonly included in high-fat postprandial inflammation studies ${ }^{(30)}$; however, one postprandial study found no change over time in overweight men ${ }^{(16)}$ or in healthy or obese women ${ }^{(36)}$. IL-8 plays an important role in atherosclerosis in part by stimulating the production of other pro-inflammatory cytokines such as TNF $\alpha$ and IL-1 $\beta^{(40)}$. Our results showed an initial rise in IL-8 concentrations after both treatments with a peak at the $3 \mathrm{~h}$ time point. An increase in IL-18 has been linked to CVD as it is a powerful cytokine whose functions include the production of pro-inflammatory cytokines such as TNF $\alpha$, IL-1 $\beta$, sICAM and soluble vascular adhesion molecule ${ }^{(41)}$. We are one of the first groups to analyse the postprandial response of IL-18 after a high-fat challenge. Our results showed a 
significant increase in IL-18 after both high-fat treatments, complemented by a similar increase in TNF $\alpha$.

TNF $\alpha$, a cytokine commonly measured in the postprandial state, significantly increased after consumption of a large lipid load and peaked at $6 \mathrm{~h}$. These data are consistent with several reports in healthy, type 2 diabetic, overweight, and obese men and women after high-fat test meals ${ }^{(15,16,35,36,38)}$. These data may be explained by a greater number of monocytes in circulation after a high-fat meal ${ }^{(42)}$ and the rise in IL- 8 and IL-18 at $3 \mathrm{~h}$. While we do not have data on lymphocyte count for this study, it would be of interest for future studies to incorporate this analysis. Our results showed a significant increase in MCP-1 from baseline at 1,3 and $6 \mathrm{~h}$ after both meals. Similar results have been reported previously in patients with the metabolic syndrome who consumed a high-saturated fat meal ${ }^{(43)}$. However, not all studies have observed this postprandial increase. Masson \& Mensink ${ }^{(16)}$ found a significant decrease in serum MCP-1 in overweight men after both highfat meals that provided a total of $50 \mathrm{~g}$ of fat (butter $v$. linoleic acid). In our study, the majority of the participants were women and fat in the test meals was provided as $50 \%$ of each individual's total energy expenditure and ranged from 45 to $75 \mathrm{~g}$. It is not known if the total amount of fat consumed or sex influence MCP-1 responses in the postprandial period.

SAA, an acute-phase protein that is primarily synthesised by the liver, increases several-fold during the inflammatory response to tissue injury ${ }^{(44)}$. Its expression is stimulated by cytokines (IL-6, IL-1 $\beta$, TNF $\alpha)^{(45)}$; however, SAA also stimulates the secretion of IL- 6 in connective tissue ${ }^{(46)}$. SAA circulates in the blood as part of HDL particles. In this complex, SAA mediates the binding of HDL to proteoglycans, promoting oxidation of the lipoprotein which impairs its ability to remove cellular cholesterol, leading to cholesterol accumulation in macrophages and foam cell formation ${ }^{(47)}$. Based on SAA's ability to stimulate release of IL-6 by some tissues, we expected to see a postprandial increase after the high-fat meals. Instead, our results indicate a significant decrease from baseline at the $6 \mathrm{~h}$ time point similar to the decline in HDL-cholesterol over the postprandial period. A similar decline in SAA concentration was observed by Esser et al. ${ }^{(48)}$ after providing healthy men a high-fat meal, while an increase was seen after the same volunteers consumed a lower-fat standard breakfast.

When the total concentration of each analyte over the $6 \mathrm{~h}$ postprandial time was calculated as the iAUC, only CRP was different between the two test meals, with the VA meal resulting in a significantly greater overall CRP concentration $(P=$ 0.033) when compared with the $\mathrm{CH}$ meal. It is unknown what components in cheese could reduce CRP concentration or what components in the vegan test meal could stimulate the increase in CRP concentration over the $6 \mathrm{~h}$ postprandial time period. Schmid et al. ${ }^{(49)}$ recently reported no difference in postprandial CRP after consumption of a high-fat control or high-fat control with milk in normal-weight, overweight and obese men. CRP is an acute-phase protein that is synthesised by the liver and increases several-fold during the inflammatory response to tissue injury ${ }^{(44)}$ and responds to diet and exercise $\mathrm{e}^{(50,51)}$. Its release by the liver is stimulated by IL-6 
and alternatively, CRP also induces secretion of IL- 6 by endothelial cells ${ }^{(52)}$. There are inconsistent findings on the effects of a high-fat test meal on circulating CRP concentrations as a result of the composition of the test meals used, target populations and timings of blood draws. For example, in lean individuals, plasma CRP measured $24 \mathrm{~h}$ after consumption of a high-fat breakfast was significantly lower from baseline when the breakfast contained a high $v$. low saturated:unsaturated fat ratio ${ }^{(15)}$. Other reports have shown that CRP does not change within $6 \mathrm{~h}$ after consumption of high-fat mixed meals in lean, overweight and abdominally obese participants ${ }^{(15,31,35,49)}$. However, in type 2 diabetic participants, CRP significantly increased from baseline within $4 \mathrm{~h}$ in response to a high-fat test meal ${ }^{(53,54)}$. In our study, the postprandial CRP response to the test meal could be explained by the interaction between metabolic phenotype and the test meal ${ }^{(31)}$. Perez-Martinez et al. ${ }^{(31)}$ recently reported higher postprandial plasma CRP to a high-fat meal in metabolically abnormal subjects compared with normal, overweight and obese, metabolically healthy patients. In our study, the majority of our participants were metabolically abnormal according to elevated circulating CRP $(>3 \mathrm{mg} / \mathrm{l})$, insulin resistance (HOMA-IR > 2.6) and abdominal adiposity, yet we did not have enough statistical power to determine the relationship between the test meal and metabolic phenotype.

In our study, participants had slightly elevated insulin concentrations at baseline as well as high total and LDL-cholesterol levels, which were expected based on the inclusion criteria. As expected, both high-fat challenges significantly increased plasma TAG concentrations postprandially; however, the concentrations surprisingly peaked at $6 \mathrm{~h}$. In metabolically healthy individuals, the peak in plasma TAG after a high-fat mixed meal occurs at about $4 \mathrm{~h}$ and declines by $6 \mathrm{~h}^{(49,55)}$. Because $70 \%$ of our study participants were insulin resistant, it is possible that the plateau in plasma TAG at 6 $\mathrm{h}$ is a result of their insulin resistance. These data are supported by the report that the postprandial plasma TAG concentration was found to plateau or peak at $6 \mathrm{~h}$ in individuals with pre-diabetes and type 2 diabetes, after consumption of a mixed meal containing $62 \mathrm{~g}$ fat ${ }^{(55)}$.

Postprandial lipaemia has been shown to be strongly associated with increased risk for coronary artery disease ${ }^{(3)}$; however, while results from our study suggest that the consumption of a meal enriched in SFA whether from Cheddar cheese or plant fat was sufficient to cause postprandial lipaemia, the postprandial cytokine response in this subject pool was within the normal range. Other studies have found that similar amounts of fat fed in mixed meals did induce a lipaemic response and elicited postprandial inflammation ${ }^{(16,36)}$. In our study, the amount of fat used was high, with a mean of $59 \mathrm{~g}$ and ranged $45-75 \mathrm{~g}$ scaled to each individual's energy intake. Thus, we expected that inflammatory responses would increase from baseline. It is possible that participants in this study had delayed changes in postprandial inflammatory markers given that their TAG levels were still increasing and possibly had not peaked yet by $6 \mathrm{~h}$.

Cross-sectionally, dairy product consumption has been shown to be inversely correlated with inflammatory markers among healthy adults ${ }^{(56)}$. There are many possibilities to explain how the myriad components in dairy products, their interactions and synergy upon digestion and metabolism could influence postprandial inflammation. Dairy components that are reported to confer anti-inflammatory effects include dairy proteins and peptides ${ }^{(57)}$; SCFA ${ }^{(11)}$ as trophic factors for intestinal cells ${ }^{(58)}$; starter and non-starter bacteria in fermented dairy products ${ }^{(12)}$; oligosaccharides as prebiotics ${ }^{(59)}$; and milk fat globule membrane and its proteins and polar lipids ${ }^{(13)}$. The effect of a meal composed of the dairy matrix as Cheddar cheese on postprandial inflammation compared with a non-dairy cheese substitute enriched with SFA in the form of palm oil has not been investigated. Palm oil was chosen as the source of SFA for the non-dairy cheese alternative arm because it is commercially available, widely consumed around the world and provides a similar SFA composition to dairy fat compared with other plant-based fats.

The lack in finding a 'treatment' effect to the high-fat test meals for several of the inflammatory markers could be explained by several limitations. First, this study was powered for postprandial changes in serum IL-6. Our sample size was not large enough to permit statistical comparisons among different metabolic phenotypic groups (i.e. high $v$. low CRP; insulin resistant $v$. sensitive, with or without the metabolic syndrome). In our study, seven participants were diagnosed with the metabolic syndrome and of the thirteen individuals without classical metabolic syndrome, most had some metabolic abnormalities: five had elevated plasma CRP, nine were insulin resistant, and ten had abdominal adiposity. Abdominal obesity is associated with a pro-inflammatory state and shares features with the metabolic syndrome (for a review, see Després \& Lemieux $\left.{ }^{(60)}\right)$, and $70 \%$ of the participants had abdominal adiposity, yet, we did not quantitatively differentiate between visceral $v$. subcutaneous obesity. Additionally, the lack of significance may also result from the timing of blood collections against the normal diurnal rhythm of inflammatory markers throughout the day ${ }^{(61)}$. We did not design the collection of time points to match the diurnal patterns of serum inflammatory markers since these patterns vary for each inflammatory marker. Yet, we did ensure that each time point was matched between the two test meals to control for the time of day. While we observed a time effect for some of the inflammatory markers it is important to note that all of these changes fell within the normal range for each marker; thus the observed changes are probably fluctuations around baseline ${ }^{(34)}$. Furthermore, one possible explanation for the lack of a treatment effect in all inflammatory markers measured is that the serum TAG had not yet peaked. Another limitation of the study is that the test meals were not balanced for dietary $\mathrm{Ca}$ in each treatment. The increased dietary $\mathrm{Ca}$ found in the $\mathrm{CH}$ meal could have formed Ca soaps and thus lowered the amount of fatty acids that were absorbed. However, while some studies found an effect of Ca from cheese on faecal fat excretion ${ }^{(62)}$, others did not ${ }^{(63)}$. Moreover, it would have been of interest to increase the sample size to allow equal numbers of men and women in the study population as little is known about the sex difference in inflammation. One study testing the inflammatory effect 
of a high-fat meal in overweight men and women found IL-6 to be significantly more elevated in women than men ${ }^{(64)}$. Finally, it is not well known if postprandial inflammation is influenced by the hormonal changes associated with the menstrual cycle as has been shown with fasting circulating lipids ${ }^{(65)}$. However, one study found that the variation contributed by the postprandial period on circulating TAG and inflammatory mediators was greater than the hormonal differences between the follicular and luteal phases ${ }^{(66)}$.

\section{Conclusions}

Results from this study provide important information about the specific effects of the dairy-derived matrix $v$. non-dairy alternative SFA as part of a mixed meal on a wide array of inflammatory markers in the postprandial state, directly addressing several key concerns and gaps in knowledge addressed by a recent expert panel. There was no evidence from this study in overweight and obese adults that there is a difference in inflammatory response after a high-fat mixed meal where the predominant fat source is cheese $v$. palm oil. From the inflammatory markers that were measured only IL-6, IL-8, IL-18, MCP-1, TNF $\alpha$ and SAA showed a postprandial response with respect to early postprandial cytokine induction, regardless of which treatment was consumed. When analysed as the iAUC, postprandial CRP was significantly lower in response to the cheese compared with the vegan test meal. Based on these results we conclude that while dietary recommendations encourage a decreased consumption of saturated fat to minimise CVD risk, saturated fat in the form of cheese lowers postprandial inflammation compared with plant sources of saturated fat.

\section{Supplementary material}

The supplementary material for this article can be found at http://www.journals.cambridge.org/10.1017/jns.2015.40

\section{Acknowledgements}

This project was made possible by support from the National Dairy Council (Rosemont, IL) and the US Department of Agriculture (USDA), Agricultural Research Service, Western Human Nutrition Research Center.

The authors would like to thank the study participants for their time and efforts to comply with the study requirements. The authors would like to thank: the Western Human Nutrition Research Center kitchen personnel Dustin Burnett, Sara Dowling and Julie Edwards; phlebotomist Jerome Crawford; and physiologist Mary Gustafson for their dedication to the project. The USDA is an equal opportunity employer and provider.

A. M. Z., J. T. S., J. B. G. and M. D. V. L. designed the research; E. D., N. R., T. S. R. and E. R. G. conducted the research; E. D. analysed the data; and E. D., A. M. Z., J. T. S. and M. D. V. L. wrote the paper. E. D. had primary responsibility for final content. All authors read and approved the final manuscript.
M. D. V. L., A. M. Z. and J. T. S. have received research funding from the National Dairy Council; A. M. Z. received a stipend from the National Dairy Council to present a talk at a symposium in 2013. The founding sponsors had no role in the design of the study; in the collection, analyses or interpretation of data; in the writing of the manuscript, and in the decision to publish the results. There are no conflicts of interest.

\section{References}

1. Burdge GC \& Calder PC (2005) Plasma cytokine response during the postprandial period: a potential causal process in vascular disease? BrJ Nutr 93, 3-9.

2. Margioris AN (2009) Fatty acids and postprandial inflammation. Curr Opin Clin Nutr Metab Care 12, 129-137.

3. Patsch JR, Miesenböck G, Hopferwieser T, et al. (1992) Relation of triglyceride metabolism and coronary artery disease. Studies in the postprandial state. Arterioscler Thromb 12, 1336-1345.

4. Keys A, Anderson J \& Grande F (1957) Prediction of serumcholesterol responses of man to changes in fats in the diet. Lancet i, 959-966.

5. Kushi LH, Lew RA, Stare FJ, et al. (1985) Diet and 20-year mortality from coronary heart disease: the Ireland-Boston Diet-Heart Study. New Engl J Med 312, 811-818.

6. Erkkilä A, de Mello VD, Risérus U, et al. (2008) Dietary fatty acids and cardiovascular disease: an epidemiological approach. Prog Lipid Res 47, 172-187.

7. McGuire S (2011) U.S. Department of Agriculture and U.S. Department of Health and Human Services, Dietary Guidelines for Americans, 2010. Washington, DC: U.S. Government Printing Office, January 2011. Adv Nutr 2, 293-294.

8. Howard BV, Van Horn L, Hsia J, et al. (2006) Low-fat dietary pattern and risk of cardiovascular disease: the Women's Health Initiative Randomized Controlled Dietary Modification Trial. JAMA 295, 655-666.

9. Qin L-Q, Xu J-Y, Han S-F, et al. (2015) Dairy consumption and risk of cardiovascular disease: an updated meta-analysis of prospective cohort studies. Asia Pac J Clin Nutr 24, 90-100.

10. Nakamura T, Hirota T, Mizushima K, et al. (2013) Milk-derived peptides, Val-Pro-Pro and Ile-Pro-Pro, attenuate atherosclerosis development in apolipoprotein E-deficient mice: a preliminary study. J Med Food 16, 396-403.

11. Sjogren P, Rosell M, Skoglund-Andersson C, et al. (2004) Milk-derived fatty acids are associated with a more favorable LDL particle size distribution in healthy men. J Nutr 134, 1729_ 1735 .

12. Settanni L \& Moschetti G (2010) Non-starter lactic acid bacteria used to improve cheese quality and provide health benefits. Food Microbiol 27, 691-697.

13. Snow D, Ward R, Olsen A, et al. (2011) Membrane-rich milk fat diet provides protection against gastrointestinal leakiness in mice treated with lipopolysaccharide. J Dairy Sci 94, 2201-2212.

14. Jacobs DR, Gross MD \& Tapsell LC (2009) Food synergy: an operational concept for understanding nutrition. Am J Clin Nutr 89, 1543S-1548S.

15. Poppitt SD, Keogh GF, Lithander FE, et al. (2008) Postprandial response of adiponectin, interleukin- 6 , tumor necrosis factor- $\alpha$, and C-reactive protein to a high-fat dietary load. Nutrition 24, 322-329.

16. Masson CJ \& Mensink RP (2011) Exchanging saturated fatty acids for $(n-6)$ polyunsaturated fatty acids in a mixed meal may decrease postprandial lipemia and markers of inflammation and endothelial activity in overweight men. J Nutr 141, 816-821.

17. National Cancer Institute (2014) Sources of Saturated Fat, Stearic Acid, \& Cholesterol Raising Fat among the US Population, 200506. Applied Research Program website, 2014. http://appliedresearch. cancer.gov/diet/foodsources/sat_fat/ (accessed November 2015). 
18. Casalena N (2011) How many Adults are Vegan in the U.S.? Vegetarian Resource Group. http://www.vrg.org/blog/2011/12/ 05/how-many-adults-are-vegan-in-the-u-s/ (accessed January 2016).

19. Dietary Guidelines Advisory Committee (2015) Scientific Report of the 2015 Dietary Guidelines Advisory Committee. Washington, DC: USDA and US Department of Health and Human Services.

20. Craig WJ \& Mangels AR (2009) Position of the American Dietetic Association: vegetarian diets. J Am Diet Assoc 109, 1266-1282.

21. Laugerette F, Furet J-P, Debard C, et al. (2012) Oil composition of high-fat diet affects metabolic inflammation differently in connection with endotoxin receptors in mice. Am J Physiol Endocrinol Metab 302, E374-EE86.

22. Grundy SM, Cleeman JI, Daniels SR, et al. (2005) Diagnosis and management of the metabolic syndrome: an American Heart Association/National Heart, Lung, and Blood Institute scientific statement. Circulation 112, 2735-2752.

23. Ascaso JF, Pardo S, Real JT, et al. (2003) Diagnosing insulin resistance by simple quantitative methods in subjects with normal glucose metabolism. Diabetes Care 26, 3320-3325.

24. Pearson TA, Mensah GA, Alexander RW, et al. (2003) Markers of inflammation and cardiovascular disease: application to clinical and public health practice: a statement for healthcare professionals from the Centers for Disease Control and Prevention and the American Heart Association. Circulation 107, 499-511.

25. Pedersen A, Sandström B \& Van Amelsvoort JMM (1997) The effect of ingestion of inulin on blood lipids and gastrointestinal symptoms in healthy females. Br J Nutr 78, 215-222.

26. Gouveia-Figueira S, Späth J, Zivkovic AM, et al. (2015) Profiling the oxylipin and endocannabinoid metabolome by UPLC-ESI-MS/MS in human plasma to monitor postprandial inflammation. PLOS ONE 10, e0132042.

27. Zivkovic AM, Telis N, German JB, et al. (2011) Dietary omega-3 fatty acids aid in the modulation of inflammation and metabolic health. Calif Agric (Berkeley) 65, 106-111.

28. Trumbo P, Schlicker S, Yates A, et al. (2002) Dietary reference intakes for energy, carbohydrate, fiber, fat, fatty acids, cholesterol, protein and amino acids. J Am Diet Assoc 102, 1621-1630.

29. Baecke J, Burema J \& Frijters J (1982) A short questionnaire for the measurement of habitual physical activity in epidemiological studies. Am J Clin Nutr 36, 936-942.

30. Herieka M \& Erridge C (2014) High-fat meal induced postprandial inflammation. Mol NutrFood Res 58, 136-146.

31. Perez-Martinez P, Alcala-Diaz JF, Delgado-Lista J, et al. (2014) Metabolic phenotypes of obesity influence triglyceride and inflammation homoeostasis. Eur J Clin Invest 44, 1053-1064.

32. Carstensen M, Thomsen C \& Hermansen K (2003) Incremental area under response curve more accurately describes the triglyceride response to an oral fat load in both healthy and type 2 diabetic subjects. Metabolism 52, 1034-1037.

33. Kleiner G, Marcuzzi A, Zanin V, et al. (2013) Cytokine levels in the serum of healthy subjects. Mediators Inflamm 2013, 434010.

34. Tulk HM \& Robinson LE (2009) Modifying the $n-6 / n-3$ polyunsaturated fatty acid ratio of a high-saturated fat challenge does not acutely attenuate postprandial changes in inflammatory markers in men with metabolic syndrome. Metabolism 58, 1709-1716.

35. Blackburn P, Després JP, Lamarche B, et al. (2006) Postprandial variations of plasma inflammatory markers in abdominally obese men. Obesity 14, 1747-1754.

36. Manning PJ, Sutherland WHF, McGrath MM, et al. (2008) Postprandial cytokine concentrations and meal composition in obese and lean women. Obesity 16, 2046-2052.

37. van Oostrom AJHHM, Sijmonsma TP, Verseyden C, et al. (2003) Postprandial recruitment of neutrophils may contribute to endothelial dysfunction. J Lipid Res 44, 576-583.

38. Nappo F, Esposito K, Cioffi M, et al. (2002) Postprandial endothelial activation in healthy subjects and in type 2 diabetic patients: role of fat and carbohydrate meals. J Am Coll Cardiol 39, 1145-1150.

39. Dandona P, Aljada A, Mohanty P, et al. (2001) Insulin inhibits intranuclear nuclear factor $\kappa \mathrm{B}$ and stimulates $\mathrm{I} \kappa \mathrm{B}$ in mononuclear cells in obese subjects: evidence for an anti-inflammatory effect? J Clin Endocrinol Metab 86, 3257-3265.

40. Baggiolini M, Moser B \& Clark-Lewis I (1994) Interleukin-8 and related chemotactic cytokines: the Giles Filley lecture. Chest 105, 3 Suppl., 95S-98S.

41. Mallat Z, Heymes C, Corbaz A, et al. (2004) Evidence for altered interleukin 18 (IL)-18 pathway in human heart failure. FASEB J 18, 1752-1754.

42. Hyson DA, Paglieroni TG, Wun T, et al. (2002) Postprandial lipemia is associated with platelet and monocyte activation and increased monocyte cytokine expression in normolipemic men. Clin Appl Thromb Hemost 8, 147-155.

43. Rosenson RS, Huskin AL, Wolff DA, et al. (2008) Fenofibrate reduces fasting and postprandial inflammatory responses among hypertriglyceridemia patients with the metabolic syndrome. Atherosclerosis 198, 381-388.

44. Pepys M \& Baltz ML (1982) Acute phase proteins with special reference to $\mathrm{C}$-reactive protein and related proteins (pentaxins) and serum amyloid A protein. Adv Immunol 34, 141-212.

45. Hagihara K, Nishikawa T, Isobe T, et al. (2004) IL-6 plays a critical role in the synergistic induction of human serum amyloid A (SAA) gene when stimulated with proinflammatory cytokines as analyzed with an SAA isoform real-time quantitative RT-PCR assay system. Biochem Biophys Res Comm 314, 363-369.

46. O'Reilly S, Cant R, Ciechomska M, et al. (2014) Serum amyloid A induces interleukin-6 in dermal fibroblasts via Toll-like receptor 2, interleukin-1 receptor-associated kinase 4 and nuclear factor- $\mathrm{\kappa B}$. Immunology 143, 331-340.

47. O'Brien KD \& Chait A (2006) Serum amyloid A: the "other" inflammatory protein. Curr Ather Rep 8, 62-68.

48. Esser D, Oosterink E, op't Roodt J, et al. (2013) Vascular and inflammatory high fat meal responses in young healthy men; a discriminative role of IL-8 observed in a randomized trial. PLOS ONE 8, e53474.

49. Schmid A, Petry N, Walther B, et al. (2015) Inflammatory and metabolic responses to high-fat meals with and without dairy products in men. Br J Nutr 113, 1853-1861.

50. Ajani UA, Ford ES \& Mokdad AH (2004) Dietary fiber and C-reactive protein: findings from National Health and Nutrition Examination Survey data. J Nutr 134, 1181-1185.

51. Milani RV, Lavie CJ \& Mehra MR (2004) Reduction in C-reactive protein through cardiac rehabilitation and exercise training. $J \mathrm{Am}$ Coll Cardiol 43, 1056-1061.

52. Hackam DG \& Anand SS (2003) Emerging risk factors for atherosclerotic vascular disease: a critical review of the evidence. JAMA 290, 932-940.

53. Carroll MF, Schade DS (2003) Timing of antioxidant vitamin ingestion alters postprandial proatherogenic serum markers. Circulation $108,24-31$.

54. Ceriello A, Assaloni R, Da Ros R, et al. (2005) Effect of atorvastatin and irbesartan, alone and in combination, on postprandial endothelial dysfunction, oxidative stress, and inflammation in type 2 diabetic patients. Circulation 111, 2518-2524.

55. Nakamura A, Monma Y, Kajitani S, et al. (2015) Effect of glycemic state on postprandial hyperlipidemia and hyperinsulinemia in patients with coronary artery disease. Heart Vessels 2015, 1-10.

56. Panagiotakos DB, Pitsavos CH, Zampelas AD, et al. (2010) Dairy products consumption is associated with decreased levels of inflammatory markers related to cardiovascular disease in apparently healthy adults: The ATTICA Study. J Am Coll Nutr 29, 357-364.

57. Baldi A, Ioannis P, Chiara P, et al. (2005) Biological effects of milk proteins and their peptides with emphasis on those related to the gastrointestinal ecosystem. J Dairy Res 72, Special no., 66-72.

58. Harsha WT, Kalandarova E, McNutt P, et al. (2006) Nutritional supplementation with transforming growth factor- $\beta$, glutamine, and short chain fatty acids minimizes methotrexate-induced injury. J Pediatr Gastroenterol Nutr 42, 53-58.

59. Gopal PK \& Gill H (2000) Oligosaccharides and glycoconjugates in bovine milk and colostrum. Br J Nutr 84, Suppl. 1, 69-74. 
60. Després J-P \& Lemieux I (2006) Abdominal obesity and metabolic syndrome. Nature 444, 881-887.

61. Agorastos A, Hauger RL, Barkauskas DA, et al. (2014) Circadian rhythmicity, variability and correlation of interleukin-6 levels in plasma and cerebrospinal fluid of healthy men. Psychoneuroendocrinology $44,71-82$

62. Soerensen KV, Thorning TK, Astrup A, et al. (2014) Effect of dairy calcium from cheese and milk on fecal fat excretion, blood lipids, and appetite in young men. Am J Clin Nutr 99, 984-991.

63. Hjerpsted J, Leedo E \& Tholstrup T (2011) Cheese intake in large amounts lowers LDL-cholesterol concentrations compared with butter intake of equal fat content. Am J Clin Nutr 94, 1479-1484.

64. Payette C, Blackburn P, Lamarche B, et al. (2009) Sex differences in postprandial plasma tumor necrosis factor- $\alpha$, interleukin- 6 , and C-reactive protein concentrations. Metabolism 58, 1593-1601.

65. Barnett JB, Woods MN, Lamon-Fava S, et al. (2004) Plasma lipid and lipoprotein levels during the follicular and luteal phases of the menstrual cycle. J Clin Endocrinol Metab 89, 776-782.

66. Bell HK \& Bloomer RJ (2010) Impact of serum estradiol on postprandial lipemia, oxidative stress, and inflammation across a single menstrual cycle. Gend Med 7, 166-178. 